\title{
Editorial
}

\section{Preface for the Special Issue "Trends in Educational Gamification: Challenges and Learning Opportunities"}

\author{
José Carlos Piñero Charlo ${ }^{1, *(0)}$, Nadja Belova ${ }^{2}{ }^{\circ}$, Eduardo Quevedo Gutiérrez $\left.{ }^{3}{ }^{(}\right)$, Alberto Zapatera Llinares ${ }^{4}{ }^{(}$,

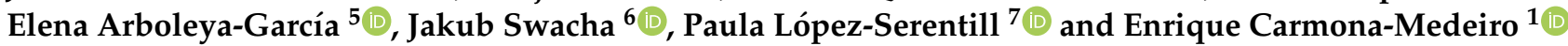

check for

updates

Citation: Piñero Charlo, J.C.; Belova,

N.; Quevedo Gutiérrez, E.; Zapatera

Llinares, A.; Arboleya-García, E.;

Swacha, J.; López-Serentill, P.;

Carmona-Medeiro, E. Preface for the

Special Issue "Trends in Educational

Gamification: Challenges and

Learning Opportunities". Educ. Sci.

2022, 12, 179. https://doi.org/

10.3390/educsci12030179

Received: 22 February 2022

Accepted: 24 February 2022

Published: 4 March 2022

Publisher's Note: MDPI stays neutral with regard to jurisdictional claims in published maps and institutional affiliations.

Copyright: (C) 2022 by the authors. Licensee MDPI, Basel, Switzerland. This article is an open access article distributed under the terms and conditions of the Creative Commons Attribution (CC BY) license (https:// creativecommons.org/licenses/by/ $4.0 /)$.
1 Department of Didactics of Mathematics, Faculty of Educational Sciences, University of Cadiz, 11510 Cádiz, Spain; enrique.carmona@uca.es

2 Department of Chemistry Education, University of Bremen, 28359 Bremen, Germany; n.belova@uni-bremen.de

3 Institute for Applied Microelectronics, Campus de Tafira, University of Las Palmas de Gran Canaria 35017 Las Palmas de Gran Canaria, Spain; eduardo.quevedo@ulpgc.es

4 Department of Educational Sciences, University CEU Cardenal Herrera, 03203 Elche, Spain; alberto.zapatera@uchceu.es

5 Department of Educational Sciences, University of Oviedo, 33005 Oviedo, Spain elenaarboleyagarcia@gmail.com

6 Institute of Management, University of Szczecin, Cukrowa 8, 71-004 Szczecin, Poland; jakub.swacha@usz.edu.pl

7 Department of Specific Didactics, University of Girona, 17080 Girona, Spain; paula.lopez@udg.edu

* Correspondence: josecarlos.pinero@gm.uca.es; Tel.: +34-660-584895

\section{Introduction}

Readers of the journal Education Sciences probably agree that playing games comes naturally - we all know how to play some game-however, because of the complexity of gaming, it is almost exclusively limited to mammals with regard to all animals: almost $80 \%$ of mammals use some sort of game for learning. Specifically with regard to humans, ever since we achieved some degree of civilization, we have played games for its proposed intellectual challenge and its entertainment value. Currently, it is difficult to participate in progressive modern societies without encountering some form of game play. In fact, the commercial video gaming industry now surpasses the movie and music industries in sales around the world, and more money is spent on games than on the other two combined. Therefore, if we consider games to be a natural activity, then applying games to education converts education into a universal activity. This is the key feature behind the use of Game-Based Learning (GBL) strategies.

In this regard, over the last ten years, the way in which education and training is delivered has considerably changed not only due to a new technologic environment-plenty of social networks, MOOCs, etc.-but also because of the appearance of new methodologies. Such new methodologies are shifting the focus from the teacher to the student, with the aims of awakening relational aspects as well as promoting imagination and divergent thinking. One new approach that holds considerable promise in helping engage learners is, indeed, game-based learning (GBL). The interest in research on GBL approaches has been continuously growing in the last decade. Particularly, since 2013, gamification in education has become a vivid and quickly developing area of research, with hundreds of new relevant publications coming out every year [1,2].

Researchers have reported that educational gamification strategies are being successfully applied in a wide variety of academic domains and educational levels, such as in studying English as second Language in higher education [3], in integrating subjects [4] such as mathematics and programming [5], or in working on mathematical and scientific problems [6]. Particularly, the skills and procedures used in certain games [7] have meaningful similarities with those used to solve mathematical problems. On the other hand, GBL 
is also used to boost relational aspects, such as increasing motivation [8], or to promote engagement with specific topics [9].

Furthermore, game design involves didactic-professional knowledge [10], so its use can deliver profit to both students and teachers and can be used to develop professional skills in future teachers. However, since teachers have a conceptual misunderstanding of gamification and STEAM education, they report insecurity and a lack of training for engaging in such educational methodologies [11]. In this regard, while a growing number of institutions are beginning to see the validity of GBL, many challenges still need to be overcome before this type of learning can become widespread.

This Special Issue of Education Sciences, titled "Trends in Educational Gamification: Challenges and Learning Opportunities", was developed to illuminate the inner workings of immersive games. Therefore, the primary aim of this Special Issue was to provide a focus for people working on the abovementioned research frames by providing a platform on which reflections on how to move gamification studies a step forward can be compiled. We invited researchers to submit original research on the deployment of gamified systems embedding novel game elements as well as rigorous quantitative and qualitative user studies that may also explore theoretical reflections grounded in empirical results. We also encouraged the scientific community to submit research covering all academic levels (preK12 to university) as well as a variety of games: board games, videogames, and live-action games, among others.

The 11 articles presented in this Special Issue deal with a wide range of aspects in Educational Gamification. We organized the discussions in a comprehensive manner so that each specific contribution can be highlighted. In this regard, as the Lead Editor and coordinator of this Special Issue, I proposed a collaborative structure to write this preface, so that experts can contribute to each of sections. Collaborative writing is a process of producing a written work as a group where all team members contributed to the content and the decisions about how the group will function. Therefore, one of my tasks as the leading editor was to coordinate and communicate with the different team members (the authors of the publications in this Special Issue) and, thus, to assign the redaction of specific sections-fitting each author's expertise - to produce and deliver a proper analysis. Finally, I highlight that the opportunity to coordinate and participate in this Special Issue has served as a great stimulus to revisiting recently conducted works and has given me the chance to work with colleagues with whom I had never conceived of sharing the same floor. I am thankful to all of the contributors of this Special Issue, and I hope to cooperate with them again in the future.

José Piñero

Lead Editor and coordinator of the SI

\section{The State-of-the-Art}

Jakub Swacha

No scientific study should begin without first checking existing knowledge. This becomes challenging in areas undergoing rapid development, such as the one covered by this Special Issue: Educational Gamification, where the sheer amount of publications is overwhelming. In this context, a bibliometric survey is useful as it enables a researcher to consider thousands of publications within a reasonable time. This fast pace comes at a price: such a survey deals only with the most easily accessible data pertaining to each document, so in most cases, it is infeasible to answer detailed research questions. However, it is perfectly capable of answering general questions such as those regarding research topics, active researchers and research institutions, and their interconnections, which is often exactly what we need to grasp what is going on in that field of study.

In the bibliometric survey on Educational Gamification presented in [1], an exclusive approach was followed in an attempt to include only work that was highly relevant to the topic (i.e., preferring false negatives over false positives). At the cost of ignoring some relevant work, this approach allowed for papers of low relevance yet high visibility, such 
as highly cited papers on gamification or education but not on Educational Gamification, to be avoided and thus to not pollute the results.

As a researcher focused on just a narrow section of Educational Gamification, pertaining to teaching computer programming, I have found the work on the bibliometric survey both revealing and rewarding, especially as some of the results were far from expected. I hope that my paper provides readers with a good picture of the field before they delve into the details presented in the excellent papers forming the rest of this Special Issue.

\section{Game Design}

\section{Eduardo Quevedo Gutiérrez and Alberto Zapatera Llinares}

Game design (applied to education) is the art of applying design and aesthetics to create a game with formative and entertainment purposes. Increasingly, elements and principles of game design are also applied to other interactions in the form of gamification. Academically, game design is part of game studies, while game theory studies strategic decision making (primarily in non-game situations). Games have historically inspired seminal research in the fields of probability, artificial intelligence, economics, and optimization theory. Applying game design to itself is a current research topic in metadesign.

The game design process associated with a computer can extend its purposes to the considered programming language. Using a simple and accessible programming language such as Scratch (proposed in our contribution as a didactic tool to teach functions) favors redesign (in Scratch, this process is known as reinvention). This scheme promotes the Creative Learning Spiral based on five components: Imagine, Create, Play, Share, and Reflect. Therefore, the authors understand that the integration of computational thinking in the school curriculum, including gamification as a methodology to implement it, promotes creativity and helps students learn the basics of programming languages. In this scope, game design serves as a means to an end. In fact, the approach carried out in our contribution considering the learning of functions through programming with Scratch is a game in and of itself. It allows the student to try different options until a problem solution is reached without fear of making mistakes in the process. This is very interesting since not being able to reach a final solution may involve the student's motivation to continue playing and improving; on the contrary, in the education system, usually mistakes are penalized, which can lead to demotivation. The authors will continue researching this topic to promote student motivation.

\section{Live-Action Games: Educational Escape Rooms Nadja Belova}

Whoever plays, steps out of everyday experience; in a sense, overrides it; and immerses themselves in a game world. This phenomenon is addressed in the concept of the "flow theory" [10]. Here, the state of "flow" is described as total absorption by a task that is both challenging and enjoyable. Such a totally immersive recent game trend is the so-called escape room. Escape rooms are a relatively new game concept that has been gaining popularity since around 2012 and can be considered a sort of hype in the science education community in the last five years. Educational Escape Rooms are a sort of live-action teambased game where players discover clues, solve puzzles, and accomplish tasks in one or more rooms in order to achieve a specific goal (usually escaping from the room) in a limited amount of time. To gain an overview of the state of science education research on this topic, we conducted a literature review. During the work in this review, subconsciously, the following questions always arose: Is this method really worth the hype? Are such immersive but also very elaborate methods really more effective-in terms of learning outcomes and competence development? As of now, it seems that the answer is that we do not know. We were able to identify not only some gaps in Educational Escape Room development (especially a need for scenarios that are easily adaptable to different educational settings) but also a major research gap when it comes to more empirical evidence on their actual effects. This is the area where research will definitely have to 
provide more results in the near future and to systematize the results because not all activities are automatically good even if everyone participates in it.

\section{Board Games}

\section{Elena Arboleya-García}

Some educators spotted that board games are under-utilized in education. Games can engage students with different learning styles and can inspire individual creativity. They create non-threatening environments through tangible elements, hands-on tasks, or mutual learning, where lower levels of knowledge and failed tasks can be turned into a meaningful-learning acquisition. However, interdisciplinarity is also needed. It offers students a better understanding of the teaching-learning processes, as they could be able to identify and connect information from the separate subjects of the school curriculum.

Based on these statements, we conceived 'The Game of The Sea' to bring marine environment and ocean knowledge closer to students. From our educative experiences, as students first and educators second, we noticed that, throughout the stages of primary and secondary education, science subjects (in particular, those related to biology) provide education that is not properly connected between each level. Therefore, students are not able to construct long-term memories about this specific topic. The design and implementation of 'The Game of The Sea' entails the creation of a network of knowledge from different levels and from different subjects (not only scientific ones) addressed in the school curriculum. Once this integrative knowledge was acquired, our students obtained a better awareness of marine environment and we could confirm that we contributed to teaching environmentally responsible citizens.

Board games and interdisciplinarity represent the missing tools in our toolboxes, in particular, with regard to secondary education. In contrast with primary education, games are usually not considered a common didactic tool by teachers in secondary education despite games providing the possibility of improving traditional lectures and their relationships with students. The research presented on this Special Issue introduces the background needed to incorporate games into school curricula and to encourage educators to embrace that possibility of adopting these tools.

\section{STEAM Education}

Paula López-Serentill

STEAM Education has recently become a trend in educational development that promotes learning throughout and for the interdisciplinary enterprise between Science, Technology, Engineering, the Arts, and Math. Teaching relevant, in-demand skills that will prepare students to become innovators in an ever-evolving world is paramount not only for the future of the students themselves but also for the future of the country. STEAM also empowers teachers to employ project-based learning that crosses each of the five disciplines and fosters an inclusive learning environment in which all students can engage and contribute. Within STEAM education, one useful tool is gamification, which is reported as a powerful tool for teachers at all levels in the educational system.

Our results show that a high percentage of math teachers think that this kind of activity has positive effects on students' development, improving their affective domain toward mathematics and required skills for mathematical competency. Notwithstanding, many teachers reported insecurity and a lack of knowledge, which is why we consider it necessary to promote STEAM training and, in particular, the use of gamification as another tool in the mathematics classroom.

\section{Conclusions}

During the last decades, we have witnessed the frenetic development of technologies, as well as the expansion and rise in the video game industry, board games, and escape rooms. The possibilities of innovating within the classroom using playful environments with didactic intentions have increased remarkably. The need for teachers to find new 
learning scenarios that align with the interests of students has led to the emergence and consolidation of two methodologies in the classroom based on the educational use of games: game-based learning and gamification. Therefore, a question emerges: How can the scientific community help these innovative movements really improve learning in the classroom?

The scientific community is responsible for exploring the educational potential of these new learning environments in depth and for providing empirical evidence on the educational possibilities they present. Although research on the educational use of games has produced results indicating that games can be healthy contributions to all educational areas, their possibilities have not yet been explored in depth. Regardless of the nature of the game (software, applications, video games, programming environments, board games, or escape rooms), more empirical evidence is required to reveal the added value of game-based learning situations compared with other types of learning. In this regard, we believe that more evidence may be of interest in progressing research on the educational use of games: especially studies on how these learning environments affect motivation and involvement, cooperation, creativity, and problem solving; studies on the different possibilities of use, specifically how they promote learning, how to practice and integrate what has been learned, how to problematize a situation, how to evaluate what has been learned, what causes triggering situations, etc.; studies that contribute to the systematization of principles for design and management; and studies on the design of disciplinary and interdisciplinary learning situations that are transferable to different educational levels, contexts, and training situations.

Finally, we believe that this Special Issue provides interesting key points that can help in understanding the effective use of educational games. In this Special Issue, the reader will find a varied and representative sample of current research issues related to the educational use of games from different disciplines, such as mathematics, music, English as second language, and marine biology, among others; to a diverse sample of games such as escape rooms, board games, and the Scratch programming environment; and to different methodological approaches, bibliometrics, bibliographic reviews, ethnographies, exploratory studies, case studies, etc.

Enrique Carmona Medeiro Guest Editor of the SI

Author Contributions: Conceptualization, supervision, writing-original draft preparation, writingreview and editing, J.C.P.C.; writing-original draft preparation, writing-review and editing, N.B., E.Q.G., A.Z.L., E.A.-G., J.S., P.L.-S. and E.C.-M. All authors have read and agreed to the published version of the manuscript.

Funding: This research received no external funding. Specific information is available on each manuscript that is included on this Special Issue.

Institutional Review Board Statement: Not applicable.

Informed Consent Statement: Not applicable.

Data Availability Statement: Data discussed on this manuscript are available on the website of the special issue: https://www.mdpi.com/journal/education/special_issues/Trends_Educational_ Gamification, accessed on 21 February 2022.

Acknowledgments: The leading editor and coordinator of this special issue would like to thank to the research groups HUM462 (Teachers' professional development) and HUM634 (Experimental Educational Psychology Laboratory) as well as to the project "Mathematical cognition and ABN methodology in the 3rd stage of the primary education" (PID2019-105584GB-I00).

Conflicts of Interest: The authors declare no conflict of interest. 


\section{References}

1. Swacha, J. State of Research on Gamification in Education: A Bibliometric Survey. Educ. Sci. 2021, 11, 69. [CrossRef]

2. Lathwesen, C.; Belova, N. Escape Rooms in STEM Teaching and Learning-Prospective Field or Declining Trend? A Literature Review. Educ. Sci. 2021, 11, 308. [CrossRef]

3. Hernández-Prados, M.; Belmonte, M.L.; Manzanares-Ruiz, J.C. How to Run Your Own Online Business: A Gamification Experience in ESL. Educ. Sci. 2021, 11, 697. [CrossRef]

4. Arboleya-García, E.; Miralles, L. 'The Game of the Sea': An Interdisciplinary Educational Board Game on the Marine Environment and Ocean Awareness for Primary and Secondary Students. Educ. Sci. 2022, 12, 57. [CrossRef]

5. Quevedo Gutiérrez, E.; Llinares, A.Z. Assessment of Scratch Programming Language as a Didactic Tool to Teach Functions. Educ. Sci. 2021, 11, 499. [CrossRef]

6. Fernández-Oliveras, A.; Espigares-Gámez, M.J.; Oliveras, M.L. Implementation of a Playful Microproject Based on Traditional Games for Working on Mathematical and Scientific Content. Educ. Sci. 2021, 11, 624. [CrossRef]

7. Antequera-Barroso, J.A.; Revuelta-Domínguez, F.-I.; Guerra Antequera, J. Similarities in Procedures Used to Solve Mathematical Problems and Video Games. Educ. Sci. 2022, 12, 172. [CrossRef]

8. Macías-Guillén, A.; Díez, R.M.; Serrano-Luján, L.; Borrás-Gené, O. Educational Hall Escape: Increasing Motivation and Raising Emotions in Higher Education Students. Educ. Sci. 2021, 11, 527. [CrossRef]

9. Vázquez-Vílchez, M.; Garrido-Rosales, D.; Pérez-Fernández, B.; Fernández-Oliveras, A. Using a Cooperative Educational Game to Promote Pro-Environmental Engagement in Future Teachers. Educ. Sci. 2021, 11, 691. [CrossRef]

10. Charlo, J.P.; García, P.O.; García, S.R. Formative Potential of the Development and Assessment of an Educational Escape Room Designed to Integrate Music-Mathematical Knowledge. Educ. Sci. 2021, 11, 131. [CrossRef]

11. López, P.; Rodrigues-Silva, J.; Alsina, Á. Brazilian and Spanish Mathematics Teachers' Predispositions towards Gamification in STEAM Education. Educ. Sci. 2021, 11, 618. [CrossRef] 